\title{
The role of adjuvants in therapeutic protection against paracoccidioidomycosis after immunization with the P10 peptide
}

\author{
Oriana Mayorga ${ }^{1}$, Julian E. Muñoz ${ }^{1}$, Nilton Lincopan ${ }^{1,2}$, Aline F. Teixeira ${ }^{1}$, Luis C. S. Ferreira ${ }^{1}$, \\ Luiz R. Travassos ${ }^{3}$ and Carlos P. Taborda ${ }^{1,4}$ *
}

\author{
1 Department of Microbiology, Biomedical Sciences Institute of University of São Paulo, São Paulo, São Paulo, Brazil \\ ${ }^{2}$ Department of Clinical Analysis, School of Pharmacy, University of São Paulo, São Paulo, São Paulo, Brazil \\ ${ }^{3}$ Department of Microbiology, Immunology and Parasitology, Federal University of São Paulo, São Paulo, São Paulo, Brazil \\ ${ }^{4}$ Laboratory of Medical Mycology-LIM53/IMTSP, University of São Paulo, São Paulo, São Paulo, Brazil
}

Edited by:

Joshua D. Nosanchuk, Albert Einstein

College of Medicine, USA

Reviewed by:

Joshua D. Nosanchuk, Albert Einstein

College of Medicine, USA

Leonardo Nimrichter, Federal

University of Rio de Janeiro, Brazil

*Correspondence:

Carlos P. Taborda, Department of

Microbiology, Biomedical Sciences Institute of University of São Paulo, Av. Prof. Lineu Prestes, 1374, São Paulo, São Paulo 05008-900, Brazil. e-mail: taborda@usp.br
Paracoccidioidomycosis (PCM), a common chronic mycosis in Latin America, is a granulomatous systemic disease caused by the thermo-dimorphic fungus Paracoccidioides brasiliensis. The glycoprotein gp43 is the main antigen target of $P$. brasiliensis and a 15mer internal peptide (QTLIAIHTLAIRYAN), known as P10, defines a major $\mathrm{CD}^{+}{ }^{+}$-specific $T$ cell epitope. Previous results have indicated that, besides having a preventive role in conventional immunizations prior to challenge with the fungus, protective anti-fungal effects can be induced in P. brasiliensis-infected mice treated with P10 administered with complete Freund's adjuvant (CFA). The peptide elicits an IFN- $\gamma$-dependent Th1 immune response and is the main candidate for effective immunotherapy of patients with PCM, as an adjunctive approach to conventional chemotherapy. In the present study we tested the therapeutic effects of P10 combined with different adjuvants [aluminum hydroxide, CFA, flagellin, and the cationic lipid dioctadecyl-dimethylammonium bromide (DODAB)] in BALB/C mice previously infected with the P. brasiliensis Pb18 strain. Significant reductions in the number of colony forming units of the fungus were detected in lungs of mice immunized with P10 associated with the different adjuvants 52 days after infection. Mice treated with DODAB and P10, followed by mice treated with P10 and flagellin, showed the most prominent effects as demonstrated by the lowest numbers of viable yeast cells as well as reductions in granuloma formation and fibrosis. Concomitantly, secretion of IFN- $\gamma$ and TNF- $\alpha$, in contrast to interleukin (IL)-4 and IL-10, was enhanced in the lungs of mice immunized with P10 in combination with the tested adjuvants, with the best results observed in mice treated with P10 and DODAB. In conclusion, the present results demonstrate that the co-administration of the synthetic P10 peptide with several adjuvants, particularly DODAB, have significant therapeutic effects in experimental PCM.

Keywords: Paracoccidioides brasiliensis, paracoccidioidomycosis, P10, adjuvants, dioctadecyl-dimethylammonium bromide, FliC flagellin, aluminum hydroxide, complete Freund's adjuvant

\section{INTRODUCTION}

Paracoccidioidomycosis (PCM) is a systemic mycosis that typically starts as a granulomatous pulmonary disease subsequent to the inhalation of conidia of the dimorphic fungus Paracoccidioides brasiliensis. When it is not diagnosed and treated properly, $P$. brasiliensis yeast cells can spread rapidly to lymph nodes, tegument, spleen, liver, and lymphoid organs of the digestive tract (Shikanai-Yasuda et al., 2006). PCM is endemic in Latin America, mostly affecting rural workers in Brazil, Colombia, and Venezuela (Wanke and Londero, 1994), and the majorities are involved in agricultural activities (Blotta et al., 1999; Restrepo et al., 2008). In Brazil, approximately 1,853 ( 51.2\%) of 3,583 confirmed deaths due to systemic mycoses from 1996 to 2006 were caused by PCM (Prado et al., 2009). gp43 is a glycoprotein of 416 amino acids (Puccia et al., 1986; Cisalpino et al., 1996). A specific T-CD4 ${ }^{+}$cell epitope was mapped to a 15 -amino acid sequence designated $\mathrm{P} 10$, which is recognized by $\mathrm{T}$ cells from mice infected with $P$. brasiliensis. Immunization of previously intratracheally infected $\mathrm{BALB} / \mathrm{c}$ mice with $\mathrm{P} 10$ reduces the fungal load in the lungs more than 200-fold as compared to non-immunized animals (Taborda et al., 1998). P10 immunized animals produced greater amounts of IFN- $\gamma$ and interleukin (IL)-12. These mice also had significantly reduced damage to lung tissue. In fact, the immune response elicited by P10 prevents the rapid spread of $P$. brasiliensis, and we have hypothesized that P10 administered as with newer adjuvants might enhance the immunoprotection by the peptide. Hence, we have begun to investigate the efficacy of different adjuvants co-administered with 
P10. Along this line, we have found FliC flagellin, derived from Salmonella enterica, can significantly modify the Th-1 immune response associated with P10 (Braga et al., 2009).

Aluminum hydroxide (Alum) is another adjuvant widely used in human and veterinary vaccines, which is highly effective in eliciting primary immune responses to target antigens. Concerning secondary responses, the adjuvant stimulates a Th2 immune response that mainly stimulates the production of antibodies. In this sense it is perhaps less suitable for vaccines against intracellular microorganisms (HogenEsch, 2002). Alum has been associated with severe local reactions such as erythema, subcutaneous nodules, and contact hypersensitivity (Baylor et al., 2002).

Promising results have been observed with complete Freund's adjuvant (CFA) and P10 (Marques et al., 2008). However, this adjuvant causes a variety of side effects such as localized injectionsite granulomas, hepatic and renal granuloma formation, and necrotizing dermatitis. Therefore, the use of CFA has been limited to experimental immunizations in animal studies. Due to the severity of adverse reactions, this adjuvant has been banned for use in humans as well as for non-experimental veterinary administration (Stills Jr., 2005).

The idea of using cationic lipids (dioctadecyl-dimethylammonium bromide, DODAB) as adjuvants arose from the effective uptake of microparticles by both dendritic cells and macrophages (Lincopan et al., 2009). Cationic polymer particles carry antigen to these phagocytes and can efficiently stimulate antibody production and activate cytotoxic T cells at low antigen dose (Singh et al., 2000; Lincopan et al., 2009). DODAB also induces maturation of dendritic cells (Thiele et al., 2001; Little et al., 2004) with high levels of IL-12 and IFN- $\gamma$ production, which may be an important benefit in the design of an anti-Paracoccidioides vaccine.

In the present work, a comparative appraisal of the various adjuvants is presented aiming to identify which compound produces the most effective immune response to P10 using murine models of PCM.

\section{MATERIALS AND METHODS ANIMALS}

Six male BALB/c mice per group (6- to 8-week old) were housed in polypropylene cages under specific pathogen free conditions. Animals used in this study were bred at University of São Paulo animal facility. All experiments involving animals were conducted and approved by the Ethics Committee of University of São Paulo and conducted in accordance with international recommendations.

\section{FUNGAL STRAIN}

Virulent $P$. brasiliensis $\mathrm{Pb} 18$ yeast cells were used to infect the animals. The strain was maintained by weekly passage on solid Sabouraud medium at $37^{\circ} \mathrm{C}$ and yeast cells were used after 710 days of growth. Before the experimental infection, the fungus was grown in modified McVeigh-Morton medium at $37^{\circ} \mathrm{C}$ for $5-$ 7 days (Restrepo and Arango, 1980). Fungal cells were washed in phosphate-buffered saline (PBS, pH 7.2) and counted in a hemocytometer. The viability of fungal suspensions was determined by staining with trypan blue (Sigma, St. Louis, MO, USA) and was always higher than $90 \%$. The virulence of the Pb18 strain was checked in each experiment by infecting BALB/c mice i.t. and recovering the yeast cells from the infected organs.

\section{INTRATRACHEAL INFECTION OF BALB/C MICE}

$\mathrm{BALB} / \mathrm{c}$ mice were inoculated i.t. with $3 \times 10^{5}$ virulent $\mathrm{Pb} 18$ yeast cells/animal, grown on Sabouraud agar and suspended in sterile saline $(0.85 \% \mathrm{NaCl})$. A maximum volume of $50 \mu \mathrm{l}$ was inoculated per mouse. Briefly, mice were anesthetized i.p. with $200 \mu \mathrm{l}$ of a solution containing $80 \mathrm{mg} / \mathrm{kg}$ ketamine and $10 \mathrm{mg} / \mathrm{kg}$ of xylazine (both from União Química Farmacêutica, Brazil). After approximately $5 \mathrm{~min}$, their necks were hyperextended, and the tracheas were exposed at the level of the thyroid and injected with $3 \times 10^{5}$ yeast cells.

\section{PEPTIDE SYNTHESIS AND PURIFICATION}

Peptide synthesis and purification was carried out at the Department of Biophysics, UNIFESP as described previously (Taborda et al., 1998). HPLC analysis showed that the synthetic P10 in the amidated form was $>90 \%$ pure.

\section{IMMUNIZATION OF MICE}

Immunization of BALB/c mice (6- to 8-week old males) was initiated 30 days after infection and repeated on days 37 and 44, by the subcutaneous route, with $20 \mu \mathrm{g}$ of P10 in presence of the respective adjuvant. The adjuvants used were CFA with subsequent immunizations with incomplete Freund's adjuvant (IFA); Alum $100 \mu \mathrm{g} / \mathrm{ml}$; FliC flagellin $5 \mu \mathrm{g} / \mathrm{animal}$, and cationic lipid at $0.1 \mathrm{mM} /$ animal. All adjuvants were vortexed with the peptide before immunization. The animals were sacrificed 7 days after the last immunization, at day 52 of infection.

\section{COLONY FORMING UNITS}

For each mouse, the lungs, spleen, and liver were excised and weighed immediately after sacrifice. Tissues were individually homogenized in PBS and $100 \mu \mathrm{l}$ of this suspension was plated on brain heart infusion medium (BHI; Difco Laboratories, Detroit, MI, USA), supplemented with $4 \%$ fetal bovine serum (Gibco, NY, USA) and $5 \%$ of the spent culture medium of $P$. brasiliensis 192 isolate (Castañeda et al., 1988), streptomycin/penicillin $10 \mathrm{IU} / \mathrm{ml}$ (Cultilab, Brazil), and cycloheximide $500 \mu \mathrm{g} / \mathrm{ml}$ (Sigma, St Louis, MO, USA). The plates were incubated at $37^{\circ} \mathrm{C}$ for a period of 10 days. The numbers of colonies were counted and results expressed in colony forming unit (CFU) per gram of tissue.

\section{CYTOKINE ANALYSIS}

Lungs of each mouse were macerated with protease inhibitor (Sigma, St Louis, MO, USA) and centrifuged; supernatants of these samples were used for cytokine detection. IL-4, IL-10, TNF$\alpha$, and IFN- $\gamma$ were measured using ELISA kits (BD Biosciences, San Diego, CA, USA). The detection limits of the assays were as follows: $7.8 \mathrm{pg} / \mathrm{ml}$ for IL-4, $31.25 \mathrm{pg} / \mathrm{ml}$ for IL-10 and IFN- $\gamma$, and $15.6 \mathrm{pg} / \mathrm{ml}$ for TNF- $\alpha$, as previously determined by the manufacturer. Cytokine levels present in the supernatant preparations were analyzed using GraphPad Prism 5. 


\section{HISTOPATHOLOGY}

The lungs were excised, fixed in 10\% buffered formalin (Merck, Germany) and submitted to histopathological analysis [(hematoxylin and eosin ( $\mathrm{H} \& \mathrm{E})$ and Masson's trichrome].

\section{STATISTICAL ANALYSIS}

Statistics was done using GraphPad Prism 5 software (San Diego, CA, USA). The results were expressed as mean values and standard deviations (SDs) of the indicated values. The non-parametric Tukey's honestly significant difference test was employed. $p$-Values of $\leq 0.05$ indicated statistical significance.

\section{RESULTS}

\section{COLONY FORMING UNITS IN INFECTED BALB/C MICE IMMUNIZED WITH PEPTIDE 10 (P10)}

After 30 days of infection, immunizations were initiated with three weekly doses of P10 with or without the different adjuvants. After 52 days of infection, the fungal load was evaluated by enumeration of CFUs from recovered organs (lung, spleen, and liver). Lungs of mice immunized with P10 along with each of the different adjuvants had a significantly reduced number of CFU compared to controls (Figure 1). The order of efficacy for CFU reduction was cationic lipid and P10 >> CFA/IFA $>$ Alum $>$ FliC. In this model, we did not recover any fungal cells from the spleens or livers of mice that received any of the immunizations with P10 (data not shown), demonstrating the effectiveness of the peptide in the control of experimental PCM. In contrast, the fungal burdens were $625 \pm 60 \mathrm{CFU} / \mathrm{g}$ of tissue in the spleens and $296 \pm 59 \mathrm{CFU} / \mathrm{g}$ of tissue in the livers of unimmunized mice.

\section{CYTOKINE PATTERN INDUCED BY IMMUNIZATION WITH P10 ASSOCIATED WITH ADJUVANTS}

In comparison with control infected animals, IFN- $\gamma$ was significantly increased in mice that received $\mathrm{P} 10$ with either cationic lipid or FliC (Figure 2A). TNF- $\alpha$ levels were significantly increased only in mice treated with P10 and cationic lipid (Figure 2B). P10 immunization with either cationic lipid or FliC significantly reduced

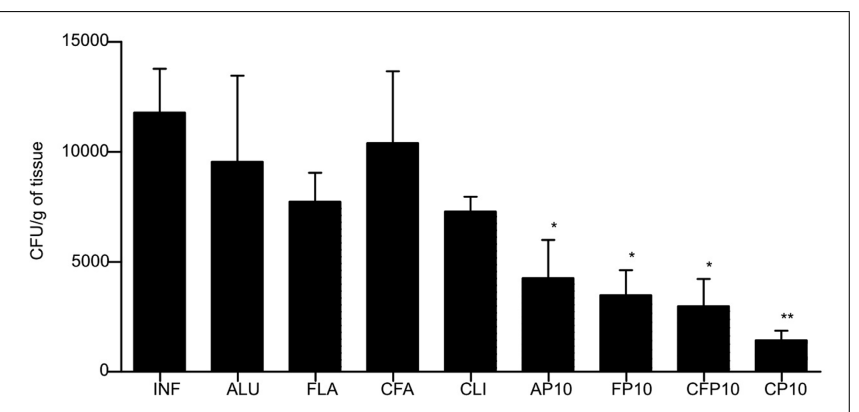

FIGURE 1 | Colony forming units (CFU) from lungs of BALB/c mice infected intratracheally with $3 \times 10^{5}$ yeast cells of $\mathrm{Pb} 18$ and immunized at 30,37 , and 44 days after infection with the different adjuvants with or without P10. Animals were sacrificed after 60 days of infection. Control animals were infected by not immunized (IFN). The adjuvants used were: aluminum hydroxide alone (ALU) or with P10 (AP10), FliC flagellin alone (FLA) or with P10 (FP10), complete Freund's adjuvant alone (CFA) or with P10 (CF10), and cationic lipid alone (CLI) or with P10 (CP10). Significant difference ${ }^{*} p<0.05,{ }^{*} p<0.01$. levels of IL-4 (Figure 2C) and IL-10 (Figure 2D). Immunization with P10 and Alum also reduced IL-10 levels, but did not significantly alter the levels of the other cytokines analyzed.

\section{LUNG HISTOPATHOLOGY IN BALB/c MICE INFECTED (i.t.) WITH Pb18 AND IMMUNIZED WITH P10}

Lung tissues from mice immunized with cationic lipid with or without P10 were stained with $\mathrm{H} \& \mathrm{E}$ and compared with unimmunized infected tissues as well as uninfected lungs (Figure 3). As expected, the non-infected group (Figure 3A) showed normal lung tissue, and the unimmunized infected lungs (Figure 3B) showed dense cell infiltrates with high numbers of fungal cells disseminated throughout the lung parenchyma. In the case of mice immunized only with the cationic lipid, we observed the formation of loose granulomas with many fungal cells (Figure 3C). In contrast, lungs of mice immunized with cationic lipid and P10 showed significantly preserved lung parenchyma without fungal cells (Figure 3D). The histological appearances of lungs from mice immunized with either FliC (Figure 3E) or Alum (Figure 3G) alone were similar to that with cationic lipid alone (Figure 3C). Immunization of mice with P10 and FliC resulted in improved granuloma formation in the lungs, which prevents the spread of the fungus, and increased preservation of normal lung parenchyma (Figure 3F). Although there was a slight increase in normal lung parenchyma in mice immunized with P10 and Alum, there was poor granuloma formation and large numbers of yeast cells within areas of inflammation (Figure 3H).

The amount of pulmonary collagen type I in mice immunized with P10 and FliC, Alum, or cationic lipid were compared with unimmunized infected controls using Masson's trichrome staining. Tissues from control mice revealed abundant collagen I fibers within cellular infiltrates containing large numbers of fungal cells (Figure 4A). Although no fungal cells were visualized, lungs of mice immunized with FliC flagellin and P10 nevertheless diffusely displayed increased amounts of collagen (Figure 4B). Mice immunized with Alum and P10 showed large granulomas containing fungal cells and the formation of collagen fibers on the granuloma's periphery (Figure 4C). In contrast, mice immunized with cationic lipid and P10 displayed preserved lung tissue without increased collagen (Figure 4D).

\section{DISCUSSION}

The P10 peptide (QTLIAIHTLAIRYAN) has important immunoprotective properties that make it a leading candidate for the development of a therapeutic vaccine (Taborda et al., 1998). We have also shown that P10 immunization can be utilized concomitantly with standard antifungal drugs in the treatment of PCM and that co-administration may also prevent disease recurrence (Marques et al., 2008).

The protective effect of $\mathrm{P} 10$ is related to the induction of an INF- $\gamma$ dependent Th-1 immune response (Taborda et al., 1998; Travassos et al., 2007), so it may be stimulated by adjuvants or nanoparticle encapsulation that increase the efficiency of P10 uptake by dendritic cells resulting in the enhanced presentation of the peptide for cellular immune responses (Amaral et al., 2010; Magalhães et al., 2012). In the present work, we show that the association of P10 with cationic lipids led to a significant reduction of 


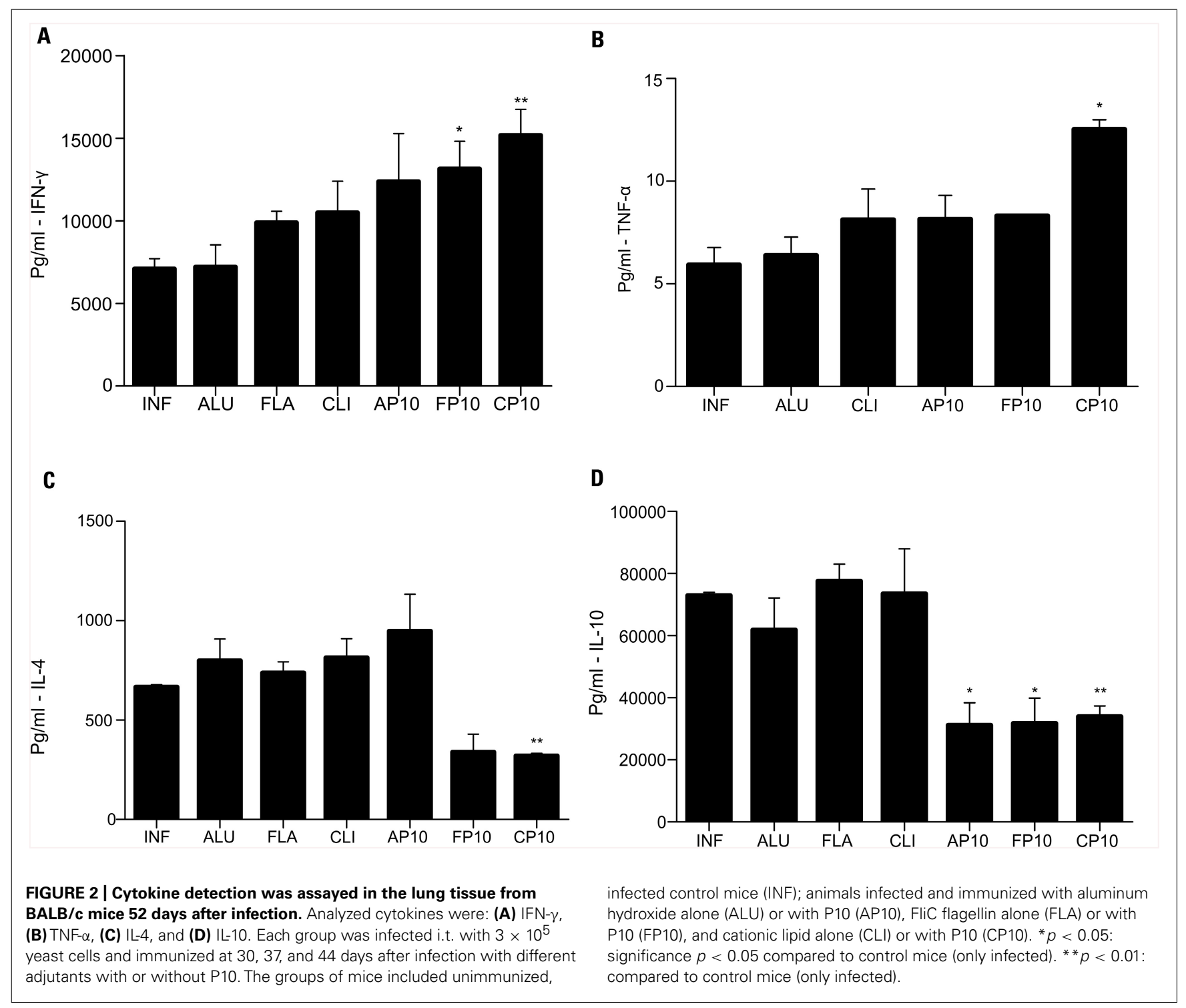

CFU in the lungs of 52-day infected animals (Figure 1). In contrast, animals immunized only with P10 (without adjuvants), had minimal reductions in fungal burden (not shown data). Hence, combining adjuvants, such as cationic lipids, with P10 can generate augmented immune responses mediated by Th-1 cells, directly related to the secretion of IFN- $\gamma$ (Figure 2A), which leads to peritoneal and lung macrophage activation as well as enhancing their fungicidal effect on yeasts and conidia of $P$. brasiliensis (BuissaFilho et al., 2008). Immunization performed with $\mathrm{P} 10$ associated with antifungal drugs in animals infected with $\mathrm{Pb} 18$, has been shown to induce a significant reduction in IL-4 (Marques et al., 2008), which we now show also occurs in the setting of immunizations with cationic lipid and P10 (Figure 2C). Moreover, P10 administration with cationic lipid also significantly reduces levels of IL-10 (Figure 2D). It is worth noting, however, that depending on the degree of inflammation generated by the Th-1 response, Th-2 cytokines are essential for balancing the immune response and reducing the risk of self-damage (Travassos et al., 2008).
Studies with cationic lipids associated with recombinant HSP of Mycobacterium leprae have demonstrated the ability of the adjuvant to promote antigen presentation in lymph node cells with production of high levels of IL-12 and INF- $\gamma$, suggesting that cationic lipid can be useful in the formulation of vaccines against intracellular bacteria, as well as against protozoa (Lincopan et al., 2009). IFN- $\gamma$ is required for the synthesis of TNF- $\alpha$ by macrophages and is essential for the accumulation of these cells and their subsequent differentiation into epithelioid cells. INF- $\gamma$ is also responsible for granuloma's formation and maintenance, and, therefore, it plays a vital role in the control of dissemination by fungi such as P. brasiliensis (Souto et al., 2000).

Although the cationic lipid/P10 association has demonstrated the best protective response in the setting of short-term infection in our murine model, it is relevant also to consider the protective effect of the association of P10 and FliC flagellin. A significant reduction in the number of CFU was observed and the cytokine profile was similar to that achieved with cationic lipid and P10 

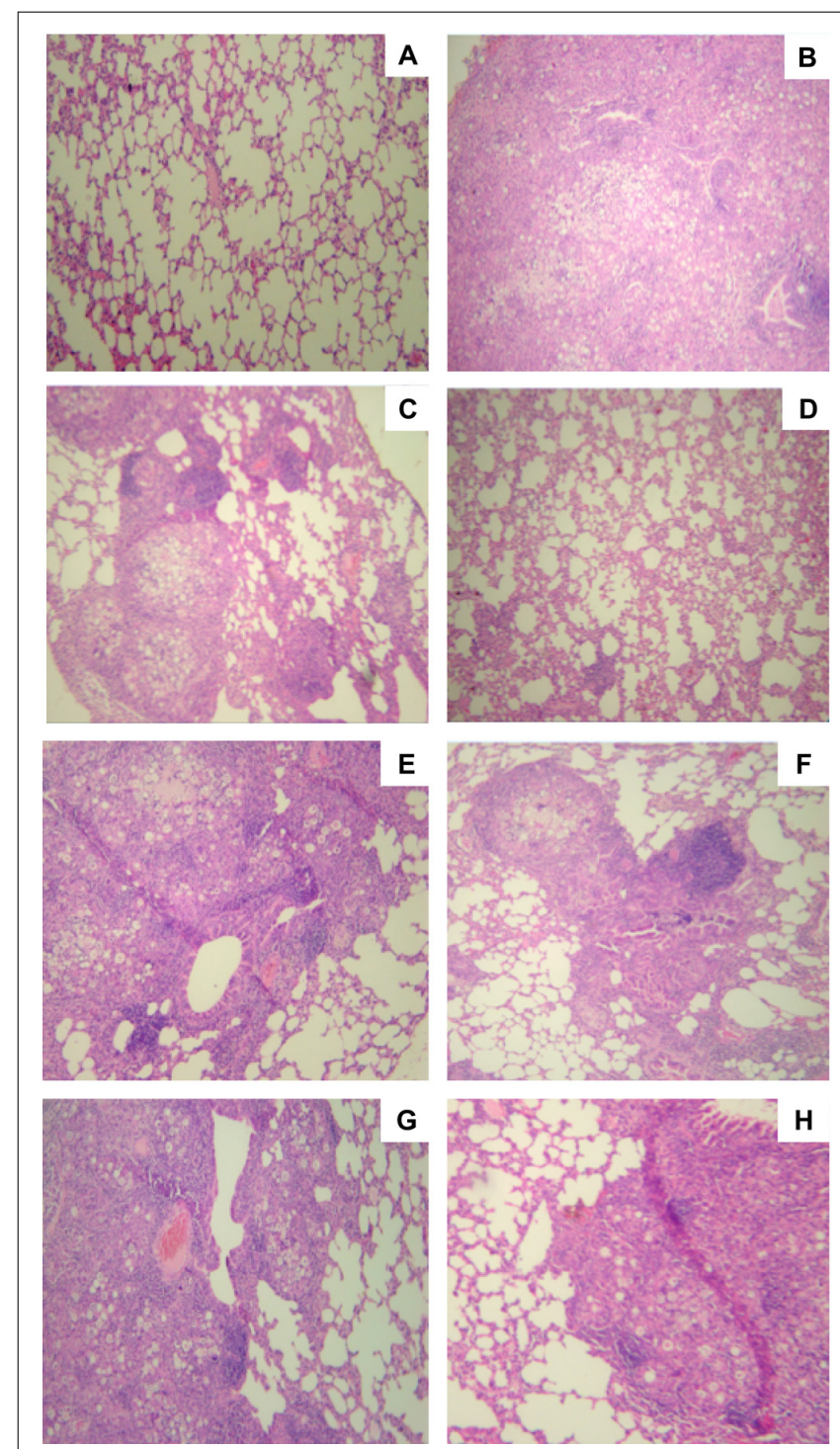

FIGURE 3 | Histological sections of murine lungs from i.t. infected BALB/c mice submitted to immunization with P10 associated to

cationic lipid. Groups of mice included (A) uninfected controls, (B) unimmunized infected controls, (C) infected and immunized only with the cationic lipid, (D) infected and immunized with cationic lipid plus P10, (E) infected and immunized only with FliC flagellin, (F) infected and immunized with FliC flagellin plus P10, (G) infected and immunized only with aluminum hydroxide, $(\mathbf{H})$ infected and immunized with aluminum hydroxide plus P10 after 52 days of infection. H\&E staining, $\times 10$ magnification.

(Figures 1 and 2). We have previously shown that prophylactic experiments performed with FliC flagellin have demonstrated the effectiveness of the association of this adjuvant with P10 allowing for the control of fungal infection in vaccinated mice (Braga et al., 2009). Intranasal immunization carried out with this formulation induced high levels of IFN- $\gamma$ and IL-12 production by lung cells and suppressed the production of Th- 2 cytokines. The formation of compact granulomas (Figure 3F) as well as cytokine levels obtained with FliC Flagellin and P10, can be associated to the administration route, since present immunizations were

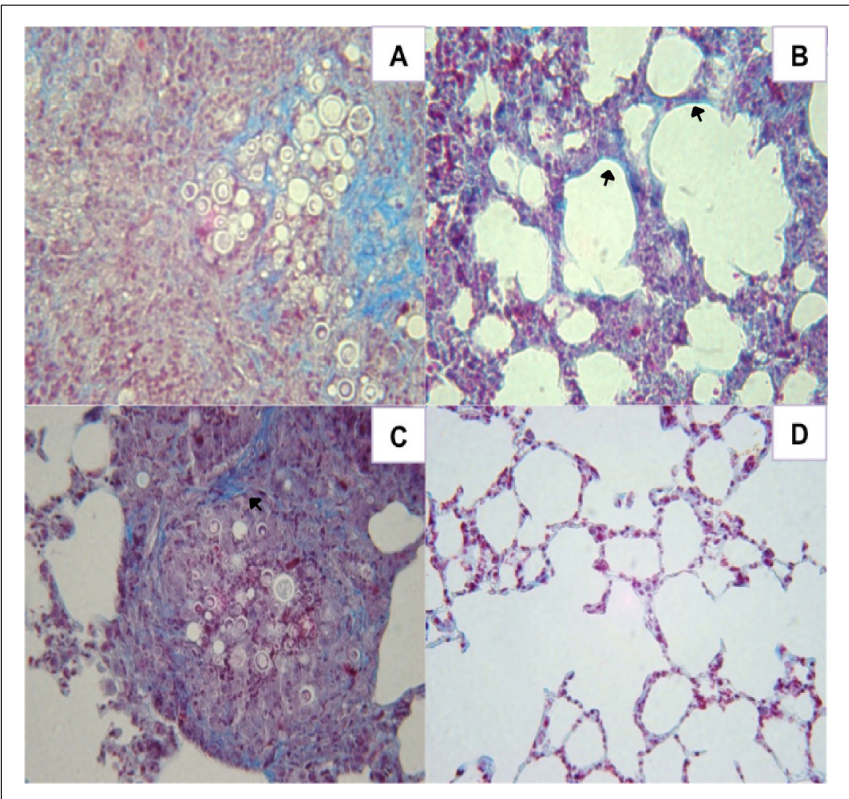

FIGURE 4 | Histological sections of murine lungs from i.t. infected $B A L B / c$ mice immunized after 30 days of infection with $P 10$ associated with FliC flagellin, aluminum hydroxide, or cationic lipid. (A) infected, unimmunized control mice, (B) infected and immunized with FliC flagellin plus P10, (C) infected and immunized with aluminum hydroxide plus P10, and (D) infected and immunized with cationic lipid plus P10 after 52 days of infection. Masson's trichrome staining, $\times 40$ magnification. Blue staining and arrows indicate type I collagen fibers.

performed subcutaneously, according to Braga et al. (2009), better results are obtained with intranasal immunizations.

In the lung parenchyma, $P$. brasiliensis induces chronic damage leading to the development of pulmonary fibrosis, which is presumably due to persistent antigenic stimulation and an ongoing active immune response. Granulomatous inflammation can increase the formation of connective tissue rich in collagen type I and III, leading to functional changes and subsequent fibrosis in the lung (Naranjo et al., 2010). Since fibrosis is a well-known sequela of PCM, it is therefore important that the adjuvants used do not induce an exacerbated inflammatory response. In fact, the association of cationic lipid and P10 resulted in a significant reduction of pulmonary fibrosis in mice infected with $\mathrm{Pb} 18$ (Figure 4D).

In summary, we have shown that the examined regimens combining P10 with different adjuvants results in significantly different protective responses. Administration of P10 with cationic lipid provided the most effective response profile, with the greatest reduction in fungal burden and a Th-1 biased cytokine response that maintained pulmonary architecture without inducing fibrotic injury.

\section{ACKNOWLEDGMENTS}

This work was supported by grants from FAPESP 11/17267-4, 09/15823-7, 09/53354-9, 07/58750-4 and CNPq 146809/2010-6. Carlos P. Taborda, Luiz R. Travassos, Luis C. S. Ferreira, and Nilton Lincopan are research fellows of the CNPq. We acknowledge the valuable scientific inputs from Dr. Joshua D. Nosanchuk. 


\section{REFERENCES}

Amaral, A. C., Marques, A. F., Muñoz, J. E., Bocca, A. L., Simioni, A. R., Tedesco, A. C., Morais, P. C., Travassos, L. R., Taborda, C. P., and Felipe, M. S. (2010). Poly(lactic acid-glycolic acid) nanoparticles markedly improve immunological protection provided by peptide P10 against murine paracoccidioidomycosis. Br. J. Pharmacol. 159, 1126-1132.

Baylor, N. M., Egan, W., and Richman, P. (2002). Aluminum salts in vaccines - US perspective. Vaccine 20, 18-23.

Blotta, M. H., Mamoni, R. L., Oliveira, S. J., Nouer, S. A., Papaiordanou, P. M., Goveia, A., and Camargo, Z. P. (1999). Endemic regions of paracoccidioidomycosis in Brazil: a clinical and epidemiologic study of 584 cases in the southeast region. Am. J. Trop. Med. Hyg. 61, 390-394.

Braga, C., Rittner, G., Muñoz, J., Teixeira, A., Massis, L., SbrogioAlmeida, M., Taborda, C., Travassos, L., and Ferreira, L. (2009). Paracoccidioides brasiliensis vaccine formulations based on the gp43-derived P10 sequence and the Salmonella enterica FliC flagellin. Infect. Immun. 77, 1700-1707.

Buissa-Filho, R., Puccia, R., Marques, A. F., Pinto, F. A., Muñoz, J. E., Nosanchuk, J. D., Travassos, L. R., and Taborda, C. P. (2008). The monoclonal antibody against the major diagnostic antigen of Paracoccidioides brasiliensis mediates immune protection in infected $\mathrm{BALB} / \mathrm{c}$ mice challenged intratracheally with the fungus. Infect. Immun. 76, 3321-3328.

Castañeda, E., Brummer, E., Perlman, A. M., Mc-Ewen, J. G., and Stevens, D. A. (1988). A culture medium for Paracoccidioides brasiliensis with high plating efficiency, and the effect of siderophores. J. Med. Vet. Mycol. 26, 351-358.

Cisalpino, P. S., Puccia, R., Yamauchi, L. M., Cano, M. I., da Silveira, J. F., and Travassos, L. R. (1996). Cloning, characterization, and epitope expression of the major diagnostic antigen of Paracoccidioides brasiliensis. J. Biol. Chem. 271, 4553-4560.

HogenEsch, H. (2002). Mechanisms of stimulation of the immune response by aluminum adjuvants. Vaccine 20 , 34-39.

Lincopan, N., Espíndola, N., Vaz, A. B., Da Costa, M., Faquim-mauro, E., and Carmona-Ribeiro, A. (2009). Novel immunoadjuvants based on cationic lipid: preparation, characterization and activity in vivo. Vaccine 27, 5760-5771.

Little, S. R., Lynn, D. M., Ge, Q., Anderson, D. G., Puram, S. V., Chen, J., Eisen, H. N., and Langer, R. (2004). Poly- $\beta$ amino estercontaining microparticles enhance the activity of nonviral genetic vaccines. Proc. Natl. Acad. Sci. U.S.A. 101, 9534-9539.

Magalhães, A., Ferreira, K. S., Almeida, S. R., Nosanchuk, J. D., Travassos, L. R., and Taborda, C. P. (2012). Prophylactic and therapeutic vaccination using dendritic cells primed with peptide 10 derived from the 43 kDa glycoprotein of Paracoccidioides brasiliensis. Clin. Vaccine Immunol. 19, 23-29.

Marques, A. F., Da Silva, M. B., Juliano, M. A. P., Travassos, L. R., and Taborda, C. P. (2008). Peptide immunization as an adjuvant to chemotherapy in mice challenged intratracheally with virulent yeast cells of Paracoccidioides brasiliensis. Antimicrob. Agents Chemother. 50, 2814-2819.

Naranjo, T. W., Lopera, D. E., DiazGranados, L., Duque, J. J., Restrepo, A., and Cano, L. E. (2010). Combined itraconazole-pentoxifylline treatment promptly reduces lung fibrosis induced by chronic pulmonary paracoccidioidomycosis in mice. Pulm. Pharmacol. Ther. 24, 81-91.

Prado, M., Silva, M. B., Laurenti, R., Travassos, L. R., and Taborda, C. P. (2009). Mortality due to systemic mycoses as a primary cause of death or in association with AIDS in Brazil: a review from 1996 to 2006. Mem. Inst. Oswaldo Cruz 104, 513-521.
Puccia, R., Schenkman, S., Gorin, P. A. J., and Travassos, L. R. (1986). Exocellular components of Paracoccidioides brasiliensis: identification of a specific antigen. Infect. Immun. 53, 193-203.

Restrepo, A., and Arango, M. D. (1980). In vitro susceptibility testing of Paracoccidioides brasiliensis to sulfonamides. Antimicrob. Agents Chemother. 18, 190-194.

Restrepo, A., Bernard, G., De Castro, C., Agudelo, C., and Tobón, A. (2008). Pulmonary paracoccidioidomycosis. Semin. Respir. Crit. Care Med. 29, 182-197.

Shikanai-Yasuda, M. A., Telles, F. F., Mendes, R. P., Colombo, A. L., and Moretti, M. L. (2006). Guidelines in paracoccidioidomycosis. Rev. Soc. Bras. Med. Trop. 39, 297-310.

Singh, M., Briones, M., Ott, G., and O'Hagan, D. (2000). Cationic microparticles: a potent delivery system for DNA vaccines. Proc. Natl. Acad. Sci. U.S.A. 97, 811-816.

Souto, J. T., Figueiredo, F., Furlanetto, A., Pfeffer, K., Rossi, M. A., and Silva, J. S. (2000). Interferon-gamma and tumor necrosis factor-alpha determine resistance to Paracoccidioides brasiliensis infection in mice. Am. J. Pathol. 156, 1811-1820.

Stills, H. F. Jr. (2005). Adjuvants and antibody production: dispelling the myths associated with Freund's complete and other adjuvants. ILAR J. 46, 280-293.

Taborda, C. P., Juliano, M. A., Puccia, R., Franco, M., and Travassos, L. R. (1998). Mapping of the T-cell epitope in the major 43-kilodalton glycoprotein of Paracoccidioides brasiliensis which induces a Th-1 response protective against fungal infection in $\mathrm{BALB} / \mathrm{C}$ mice. Infect. Immun. 66, 786-793.

Thiele, L., Rothen-Rutishauser, B., Jilek, S., Wunderli-Allenspach, H., Merkle, H. P., and Walter, E. (2001). Evaluation of particle uptake in human blood monocyte-derived cells in vitro. Does phagocytosis activity of dendritic cells measure up with macrophages? J. Control. Release 76, 59-71.
Travassos, L. R., Goldman, G., Taborda, C. P., and Puccia, R. (2007). "Insights in Paracoccidioides brasiliensis pathogenicity," in New Insights in Medical Mycology, ed. K. Kavanagh (Dordrecht: Springer), 241-265.

Travassos, L. R., Taborda, C. P., and Colombo, A. L. (2008). Treatment options for paracoccidioidomycosis and new strategies investigated. Expert Rev. Anti Infect. Ther. 6, 251-262.

Wanke, B., and Londero, A. T. (1994). "Epidemiology and paracoccidioidomycosis infection," in Paracoccidioidomycosis, eds M. Franco, C. S. Lacaz, A. Restrepo-Moreno, and G. del Negro (Boca Raton: CRC Press), 109-120.

Conflict of Interest Statement: The authors declare that the research was conducted in the absence of any commercial or financial relationships that could be construed as a potential conflict of interest.

Received: 02 April 2012; accepted: 03 April 2012; published online: 04 May 2012.

Citation: Mayorga O, Muñoz JE, Lincopan N, Teixeira AF, Ferreira LCS, Travassos LR and Taborda CP (2012) The role of adjuvants in therapeutic protection against paracoccidioidomycosis after immunization with the P10 peptide. Front. Microbio. 3:154. doi: 10.3389/fmicb.2012.00154

This article was submitted to Frontiers in Fungi and Their Interactions, a specialty of Frontiers in Microbiology.

Copyright (c) 2012 Mayorga, Muñoz, Lincopan, Teixeira, Ferreira, Travassos and Taborda. This is an openaccess article distributed under the terms of the Creative Commons Attribution Non Commercial License, which permits non-commercial use, distribution, and reproduction in other forums, provided the original authors and source are credited. 